\title{
Article \\ Choroidal Vascularity Features in Patients with Choroideremia and Cystoid Spaces
}

\author{
Claudio Iovino ${ }^{1,+}{ }^{,}$Valentina Di Iorio ${ }^{1,+}{ }^{+}$, Francesco Testa ${ }^{1}$, Viviana Bombace ${ }^{1}$, Paolo Melillo ${ }^{1}{ }^{1}$, \\ Kiran Kumar Vupparaboina ${ }^{2}$, Jay Chhablani ${ }^{3}$ and Francesca Simonelli ${ }^{1, *}$ \\ 1 Eye Clinic, Multidisciplinary Department of Medical, Surgical and Dental Sciences, \\ University of Campania 'Luigi Vanvitelli', Via Pansini 5, 80131 Naples, Italy; \\ claudio.iovino1@unicampania.it (C.I.); valentina.diiorio@unicampania.it (V.D.I.); \\ francesco.testa@unicampania.it (F.T.); viviana.bombace@gmail.com (V.B.); \\ paolo.melillo@unicampania.it (P.M.) \\ 2 Smt. Kanuri Santhamma Centre for Vitreo-Retinal Diseases, L V Prasad Eye Institute, \\ Hyderabad 500034, India; Kiran1559@gmail.com \\ 3 Department of Ophthalmology, University of Pittsburgh Medical Center, Pittsburgh, PA 15213, USA; \\ jay.chhablani@gmail.com \\ * Correspondence: francesca.simonelli@unicampania.it; Tel.: +39-081-7704501 \\ + These authors contributed equally to this work.
}

Citation: Iovino, C.; Di Iorio, V.; Testa, F.; Bombace, V.; Melillo, P.; Vupparaboina, K.K.; Chhablani, J.; Simonelli, F. Choroidal Vascularity Features in Patients with Choroideremia and Cystoid Spaces. Diagnostics 2021, 11, 382. https:// doi.org/10.3390/diagnostics11030382

Academic Editor: Takashi Kojima

Received: 2 February 2021

Accepted: 21 February 2021

Published: 24 February 2021

Publisher's Note: MDPI stays neutral with regard to jurisdictional claims in published maps and institutional affiliations.

Copyright: (c) 2021 by the authors. Licensee MDPI, Basel, Switzerland. This article is an open access article distributed under the terms and conditions of the Creative Commons Attribution (CC BY) license (https:// creativecommons.org/licenses/by/ $4.0 /)$.

\begin{abstract}
Cystoid spaces (CSs) are a common retinal finding in choroideremia (CHM) patients. The aim of this study was to analyze the vascular features of the choroid associated with the presence of CSs in patients with confirmed genetic diagnosis of CHM. A total of 33 patients (33 eyes) were enrolled in this retrospective cross-sectional study and divided into two groups based on the presence (17 eyes) or absence (16 eyes) of CSs. Choroidal features were evaluated on spectral-domain optical coherence tomography including subfoveal choroidal thickness (CT), total choroidal area (TCA), luminal choroidal area (LCA), and stromal choroidal area (SCA). The choroidal vascularity index (CVI) was then calculated in all study eyes. All structural choroidal parameters were calculated both on the entire length of the B-scan and in the central subfoveal $1500 \mu \mathrm{m}$. The average age was $37.3 \pm 11.6$ and $31.4 \pm 16.7$ years $(p=0.25)$ and mean $\operatorname{logMAR}$ best-corrected visual acuity was $0.11 \pm 0.20$ and $0.20 \pm 0.57(p=0.54)$ in the CHM groups with and without CSs, respectively. There were no significant differences in subfoveal CT, and TCA, LCA, SCA, and CVI evaluated on either the entire scan or in the central $1500 \mu \mathrm{m}$ (all $p>0.05$ ). All choroidal vasculature parameters exhibited no significant differences between CHM eyes with and without CSs. Our results suggest that the choroid may not be involved in the development of CSs in patients with CHM.
\end{abstract}

Keywords: choroidal vascularity index; choroideremia; cystoid macular edema; cystoid space

\section{Introduction}

Choroideremia (CHM) is an X-linked chorioretinal dystrophy characterized by a diffuse, progressive atrophy of the choroid, retinal pigment epithelium (RPE), and retina [1]. The exact pathogenesis of the disease has not been completely elucidated. It is unclear whether the initial events primarily begin in the RPE progressing into the degeneration of the choroid and photoreceptors, or the photoreceptors are involved first, followed by RPE and choroid impairment $[1,2]$.

$\mathrm{CHM}$ is remarkable for chronic progressive visual loss, including early onset night blindness and peripheral visual field reduction $[3,4]$. Patients usually retain good central visual acuity into the fifth decade of life, despite structural alterations of the central retina in the early stage of the disease $[5,6]$.

Cystoid spaces (CSs) are a common retinal finding in CHM patients, with a prevalence of up to $63 \%$ as detected by spectral-domain optical coherence tomography (SD-OCT) [7]. 
The pathogenesis of CSs in eyes with CHM is not well understood, and different mechanisms have been proposed including Muller cell degeneration, blood-retinal barrier disruption, and RPE dysfunction [8]. To date, there has been limited investigation of the choroid in relation to the presence of CSs in patients with CHM. The choroidal vascularity index (CVI) provides the capability to calculate quantitative parameters of the choroid and stratify the stromal and vascular components $[9,10]$.

Recently, Murro et al. reported no differences in the CVI between young CHM patients and controls [11]. Nevertheless, they did not make any distinctions between eyes with or without intraretinal cysts. Conversely, the choroid was proposed to be an important factor to consider in the etiology of cystoid macular edema (CME) in patients with retinitis pigmentosa (RP) [12].

The aim of this study was to examine in detail the vascular features of the choroid associated with the presence of intraretinal CSs in patients with confirmed genetic diagnosis of CHM.

\section{Methods}

In this cross-sectional study, patients with CHM were retrospectively evaluated at the Referral Center of Hereditary Retinal Dystrophies of the University of Campania "Luigi Vanvitelli." Institutional review board approval was obtained for a retrospective consecutive chart review. The study adhered to the guidelines of the Health Insurance Portability and Accountability Act and was performed in accordance with the tenets of the Declaration of Helsinki.

\subsection{Patients and Clinical Examination}

Patients with a confirmed genetic diagnosis of $\mathrm{CHM}$ were reviewed and divided into two groups based on the presence or absence of CSs.

Clinical diagnosis of CHM was based on the patient's history of nyctalopia and /or hemeralopia, presence of the characteristic fundus findings (including choroidal and RPE degenerative changes throughout the posterior pole and mid-peripheral retina), variable degree of peripheral field restriction, and electroretinogram (ERG) abnormalities. In all patients, DNA and total RNA were extracted from peripheral blood leukocytes and exons 1 to 15 of the CHM gene were amplified by PCR as previously described [13].

CSs were defined as one or more fluid-filled, intraretinal cysts in the macula as detected by volumetric SD-OCT. In patients with bilateral CSs, the eye with greater central macular thickness (CMT) was selected for analysis.

In CHM patients without CSs, the eye with the best quality image was selected for the analysis.

Exclusion criteria included the presence of any other retinal disease or ocular disorder that could affect choroidal thickness (CT) or could be associated with the development of CSs (e.g., recent history of cataract and/or vitreoretinal surgery in the previous 6 months), hyperopia, or myopia $>6$ diopters. Additionally, patients with media opacities that could influence image quality were also excluded from the study.

For eligible patients, deidentified medical records and multimodal imaging findings were comprehensively reviewed. All patients underwent a complete ophthalmological examination encompassing the Snellen best-corrected visual acuity (BCVA) with logMAR conversion for statistical analysis, slit-lamp biomicroscopy of anterior segment and fundus examination, intraocular pressure, Goldman visual field (GVF), full-field ERG by corneal contact lens electrodes with a Ganzfeld stimulator (Roland Consult, Brandenburg an der Havel, Germany), and SD-OCT and fundus autofluorescence (Heidelberg Spectralis HRA + OCT; Heidelberg Engineering, Germany). Microperimetry was performed by an automatic fundus-related perimeter (MP1 Microperimeter, Nidek Technologies, Padova, Italy). History of any medication for the intraretinal fluid was also investigated, considering the potential influence of some drugs (anti-vascular endothelial growth factors, carbonic anhydrase inhibitors, etc.) on the choroidal vasculature. 


\subsection{OCT Analysis of the Retina and Choroid}

A $20^{\circ} \times 20^{\circ}$ volume scan was obtained for all study eyes and the horizontal $6 \mathrm{~mm}$ B-scan section through the central fovea was used for the analysis, as it is representative of the total macular choroidal vascularity [14]. CMT was automatically displayed by the thickness profile module.

Subfoveal CT was manually measured on the horizontal foveal OCT B scan using the caliper tool of the built-in automated software as the distance between Bruch's membrane interface and the sclerochoroidal interface.

The exact location of the CSs in the retinal layers was recorded using horizontal linear OCT B-scans. The ellipsoid zone (EZ) and external limiting membrane (ELM) integrity were evaluated in the foveal $1500 \mu \mathrm{m}$ and in the area under the intraretinal fluid. The presence of outer retina tubulations (ORTs) was also ascertained.

The CVI was calculated using the previously reported automated algorithm that included initial denoising with localization of the choroidal inner and outer boundaries [15-17]. To allow computation of the luminal choroidal area (LCA) and stromal choroidal area (SCA), the OCT B-scan passing through the fovea was binarized and choroidal components were segmented. The bright regions were labelled as SCA and the dark regions as LCA. Total choroidal area (TCA) was measured as the sum of the SCA and LCA, and the CVI was calculated as the ratio of LCA over TCA. All choroidal parameters were calculated both on the entire length of the B-scan $(6 \mathrm{~mm})$ and in the subfoveal $1500 \mu \mathrm{m}$ (Figure 1).

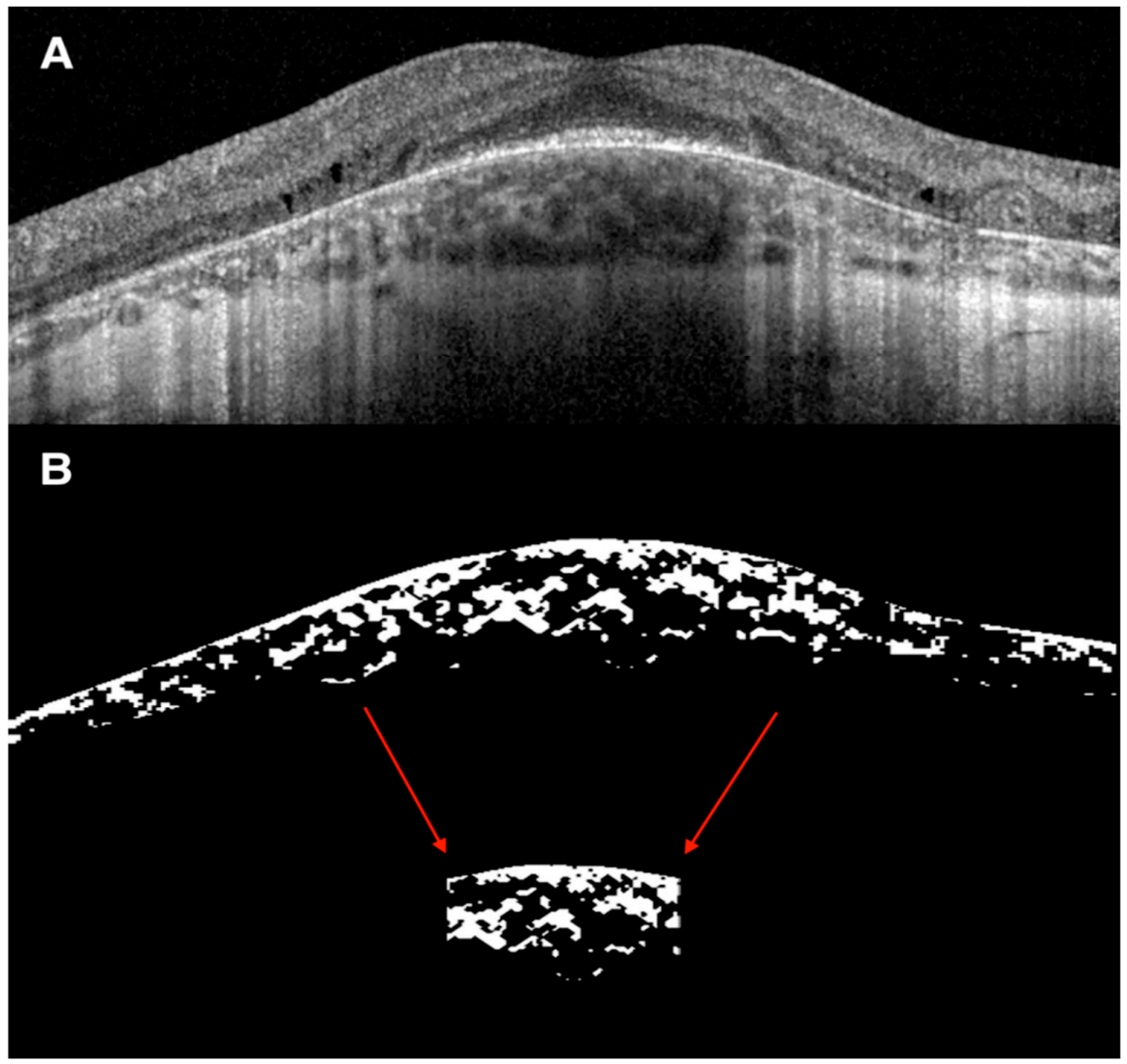

Figure 1. Representative case of choroidal vascularity index (CVI) evaluation on spectral-domain optical coherence tomography (SD-OCT) image. (A) SD-OCT $20^{\circ}$ or $6 \mathrm{~mm} \mathrm{~B} \mathrm{scan} \mathrm{of} \mathrm{a} \mathrm{21-year-old} \mathrm{man} \mathrm{with} \mathrm{CHM} \mathrm{and} \mathrm{intraretinal} \mathrm{cysts} \mathrm{in}$ the inner nuclear layer with underlying disruption of the outer retinal layers. (B) Binarized SD-OCT $20^{\circ}$ or $6 \mathrm{~mm} \mathrm{~B} \mathrm{scan}$ image showing the total choroidal area (TCA) measured as the sum of the stromal choroidal area (bright regions) and the luminal choroidal area or LCA (dark regions). The CVI was calculated as the ratio of LCA over TCA. The same choroidal parameters were measured on the subfoveal $1500 \mu \mathrm{m}$ (red arrows). 


\subsection{Statistical Analysis}

Continuous variables are reported as mean \pm standard deviation (SD) and categorical variables are reported as counts (percentage). T-tests and Fisher's exact tests were adopted to explore differences in the study parameters between the patients with and without CSs for continuous and categorical variables, respectively. In order to correct for multiple comparisons, $p$-values were compared with Benjamini-Hochberg's (BH) adjusted $\alpha$ with a false discovery rate of $5 \%$.

\section{Results}

A total of 33 patients (33 eyes) from 26 families met the inclusion criteria and were divided into two groups based on the presence (17 eyes) or absence (16 eyes) of CSs. The pathogenic mutations of the CHM gene are shown in Table 1.

Table 1. Genetic features of choroideremia patients.

\begin{tabular}{|c|c|c|}
\hline ID & Presence of Cystoid Spaces & $\begin{array}{c}\text { CHM Pathogenic Variant } \\
\text { (NM_000390.3; NP_000381.1) }\end{array}$ \\
\hline P1 & YES & c. $940+1 G>T$ \\
\hline $\mathrm{P} 2$ & YES & c. $1-? * 3450+? \mathrm{del}$ \\
\hline P3 & YES & c.1520A > G (p.His507Arg) \\
\hline $\mathrm{P} 4$ & YES & Deletion encompassing exons 6 and 7 \\
\hline P5 & YES & c.1414-?_1510+?del \\
\hline P6 & YES & c.1414-?_1510+?del \\
\hline P7 & YES & c. $1166+1 G>C$ \\
\hline P8 & YES & c. $1166+1 G>C$ \\
\hline P9 & YES & c.315_318del (p.Ser105Argfs) \\
\hline P10 & YES & c.580_581ins (p.Asp184Glufs) \\
\hline P11 & YES & c.1029delG (p.Met343llefs) \\
\hline P12 & YES & c.106 + 1G > T (p.Gly17Glufs37*) \\
\hline P13 & YES & c.877C > T (p.Arg293*) \\
\hline P14 & YES & c.877C > T (p.Arg293*) \\
\hline P15 & YES & c.1651delTACTT \\
\hline P16 & YES & c.(?_49+1)_(1609+1_1610-1)del \\
\hline P17 & YES & c.877C > T (p.Arg293*) \\
\hline P18 & NO & Deletion encompassing exons 6 and 7 \\
\hline P19 & NO & Deletion encompassing exons 6 and 7 \\
\hline P20 & NO & c.525_526del(p.Glu177Lysfs) \\
\hline P21 & $\mathrm{NO}$ & c.580_581ins (p.Asp184Glufs) \\
\hline P22 & NO & c. $941-2 \mathrm{~A}>\mathrm{G}$ \\
\hline $\mathrm{P} 23$ & NO & c.969T > A (p.Tyr323*) \\
\hline $\mathrm{P} 24$ & NO & c. $808 \mathrm{C}>\mathrm{T}\left(\mathrm{p} . \operatorname{Arg} 270^{*}\right)$ \\
\hline P25 & NO & c.969T > A (p.Tyr323*) \\
\hline P26 & NO & c.(?_49+1)_(1609+1_1610-1)del \\
\hline P27 & $\mathrm{NO}$ & c. $1350-1 \mathrm{G}>\mathrm{A}$ \\
\hline P28 & NO & c.969T > A (p.Tyr323*) \\
\hline P29 & NO & c. $820-2 \mathrm{~A}>\mathrm{G}$ \\
\hline P30 & NO & c.1245-?_1962+ del ${ }^{*}($ p.Cys416*) \\
\hline P31 & $\mathrm{NO}$ & c.31S_318del, p. Ser10Sfs \\
\hline P32 & NO & c.315_318del \\
\hline P33 & $\mathrm{NO}$ & c.1029delG (p.Met343llefs) \\
\hline
\end{tabular}


All patients' demographics and retinal and choroidal characteristics of the study participants are summarized in Table 2.

Table 2. Patients demographics and comparison of structural retinal and choroidal characteristics between CHM patients with and without CSs.

\begin{tabular}{|c|c|c|c|c|}
\hline & $\begin{array}{l}\text { CHM Eyes with CSs } \\
\qquad(n=17)\end{array}$ & $\begin{array}{l}\text { CHM Eyes without CSs } \\
\qquad(n=16)\end{array}$ & $p$-Value & B-H Adjusted $\alpha$ \\
\hline Age (Avg \pm STD $)$ & $37.3 \pm 11.6$ & $31.4 \pm 16.7$ & 0.25 & 0.020 \\
\hline BCVA (LogMAR, Avg \pm STD) & $0.11 \pm 0.20$ & $0.20 \pm 0.57$ & 0.54 & 0.043 \\
\hline $\begin{array}{l}\text { Central macular thickness } \\
\quad(\mu \mathrm{m}, \mathrm{Avg} \pm \mathrm{STD})\end{array}$ & $272.3 \pm 57.7$ & $232.1 \pm 69.3$ & 0.08 & 0.007 \\
\hline $\begin{array}{l}\text { Sub-foveal choroidal thickness } \\
(\mu \mathrm{m}, \text { Avg } \pm \text { STD })\end{array}$ & $187.9 \pm 71.9$ & $215.6 \pm 67.9$ & 0.26 & 0.023 \\
\hline $\begin{array}{l}\text { Ellipsoid zone integrity in the foveal } \\
\text { region }(\#, \%)\end{array}$ & $8(47.1 \%)$ & $12(75.0 \%)$ & 0.16 & 0.013 \\
\hline $\begin{array}{c}\text { External limiting membrane integrity in } \\
\text { the foveal region }(\#, \%)\end{array}$ & $11(64.7 \%)$ & $12(75.0 \%)$ & 0.71 & 0.050 \\
\hline Tubulation (\#, \%) & $17(100 \%)$ & $11(68.7 \%)$ & 0.02 & 0.003 \\
\hline
\end{tabular}

Data are expressed as mean \pm standard deviation or counts (frequency) for continuous and categorical variables, respectively. CHM = choroideremia, CSs = cystoid spaces, Avg = Average, STD = Standard deviation, BCVA = best corrected visual acuity.

Neither group exhibited any significant differences as pertaining to age and BCVA. In the CS group, intraretinal cysts were unilateral in 10 eyes $(58.8 \%)$ and bilateral in 7 eyes $(41.2 \%)$. None of the patients with intraretinal cysts were taking any medication.

\section{OCT Analysis of the Retina and Choroid}

In the CS group, cysts were located exclusively in the inner nuclear layer (INL). Analysis of the outer retinal bands in the subfoveal $1500 \mu \mathrm{m}$ revealed no statistical differences as for EZ and ELM integrity (all $p>0.05$, Table 2).

Moreover, analysis of the outer retinal bands under the cysts revealed that ELM and EZ were intact only in 2 eyes $(11.8 \%)$.

As expected, the mean CMT was greater in the CS group with intraretinal cysts $(272.3 \pm 57.7$ vs. $232.1 \pm 69.3)$, albeit the difference was not statistically significant $(p=0.08$, Table 2). Conversely, mean subfoveal CT was greater in the CHM group without versus with CSs but still not significant ( $p=0.26$, Table 2$)$. ORTs were present in 17 eyes $(100 \%)$ in the CS group and 11 eyes (68.7\%) in the group without cysts, and the difference was statistically significant $(p=0.02)$.

All data for choroidal vasculature analysis are summarized in Table 3.

TCA, LCA, and SCA were all lower in the CHM eyes with CSs in both $6 \mathrm{~mm}$ and $1500 \mu \mathrm{m}$ choroidal analysis, although the difference was not significant (all $p>0.05$, Table 3 ). In the CHM group with intraretinal cysts, CVI was slightly greater for either $6 \mathrm{~mm}$ or $1500 \mu \mathrm{m}$ evaluation ( $p>0.05$, Table 3$)$. 
Table 3. Choroidal parameters in CHM patients with and without CSs in the total $6 \mathrm{~mm}$ scan and central $1500 \mu \mathrm{m}$ under the fovea.

\begin{tabular}{|c|c|c|c|c|}
\hline $\begin{array}{l}\text { Choroidal Parameters for the Total } \\
\qquad 6 \mathrm{~mm} \text { Scan }\end{array}$ & $\begin{array}{l}\text { CHM Eyes With CSs } \\
\qquad(n=17)\end{array}$ & $\begin{array}{l}\text { CHM Eyes Without CSs } \\
\qquad(n=16)\end{array}$ & $p$-Value & B-H Adjusted $\alpha$ \\
\hline $\begin{array}{l}\text { Choroidal Vascularity Index } \\
\quad(\%, \mathrm{Avg} \pm \mathrm{STD})\end{array}$ & $68.1 \pm 4.4$ & $66.4 \pm 4.0$ & 0.28 & 0.034 \\
\hline $\begin{array}{l}\text { Total Choroidal Area for } \\
\left(\mathrm{mm}^{2}, \text { Avg } \pm \text { STD }\right)\end{array}$ & $0.89 \pm 0.43$ & $1.09 \pm 0.59$ & 0.28 & 0.030 \\
\hline $\begin{array}{l}\text { Luminal Choroidal Area } \\
\left(\mathrm{mm}^{2}, \text { Avg } \pm \text { STD }\right)\end{array}$ & $0.61 \pm 0.29$ & $0.71 \pm 0.38$ & 0.36 & 0.037 \\
\hline $\begin{array}{l}\text { Stromal Choroidal Area } \\
\left(\mathrm{mm}^{2}, \operatorname{Avg} \pm \text { STD }\right)\end{array}$ & $0.29 \pm 0.15$ & $0.37 \pm 0.22$ & 0.21 & 0.017 \\
\hline \multicolumn{5}{|l|}{$\begin{array}{l}\text { Choroidal Parameters for the } 1500 \mu \mathrm{m} \\
\text { under the fovea }\end{array}$} \\
\hline $\begin{array}{l}\text { Choroidal Vascularity Index } \\
(\%, \mathrm{Avg} \pm \mathrm{STD})\end{array}$ & $70.4 \pm 6.1$ & $67.4 \pm 5.0$ & 0.14 & 0.010 \\
\hline $\begin{array}{l}\text { Total Choroidal Area for } \\
\quad\left(\mathrm{mm}^{2}, \operatorname{Avg} \pm \mathrm{STD}\right)\end{array}$ & $0.28 \pm 0.13$ & $0.31 \pm 0.15$ & 0.61 & 0.047 \\
\hline $\begin{array}{l}\text { Luminal Choroidal Area } \\
\qquad\left(\mathrm{mm}^{2}, \operatorname{Avg} \pm \mathrm{STD}\right)\end{array}$ & $0.18 \pm 0.09$ & $0.2 \pm 0.1$ & 0.52 & 0.040 \\
\hline $\begin{array}{l}\text { Stromal Choroidal Area } \\
\left(\mathrm{mm}^{2}, \text { Avg } \pm \text { STD }\right)\end{array}$ & $0.08 \pm 0.05$ & $0.1 \pm 0.06$ & 0.26 & 0.024 \\
\hline
\end{tabular}

Data are expressed as mean \pm standard deviation. $\mathrm{CHM}=$ choroideremia, $\mathrm{CSs}=$ cystoid spaces, Avg = average, $\mathrm{STD}=$ standard deviation.

\section{Discussion}

Intraretinal cysts represent a common ocular complication in patients with inherited retinal diseases including $\mathrm{CHM}, \mathrm{RP}$, gyrate atrophy, enhanced S-cone syndrome, and Xlinked retinoschisis [18]. The prevalence of cystoid changes in eyes with CHM ranges from $20 \%$ to $63 \%$ as detected by SD-OCT $[5,7]$.

Various factors and mechanisms have been proposed for the onset of CSs in CHM patients including impairment of the blood-retinal barrier, tangential vitreous traction, and Muller cells degeneration [7]. Although all these mechanisms might work in aggregate, involvement of the choroid in the pathophysiology of the intraretinal fluid has been discussed minimally in the literature.

To our knowledge, this is the first study that investigates the potential involvement of the choroid in the development of intraretinal cysts in patients with CHM. We found no significant differences in terms of subfoveal CT, CVI, and all subcomponents (TCA, SCA, and LCA) between eyes with and without CSs, and this was true for both $6 \mathrm{~mm}$ and $1500 \mu \mathrm{m}$ analyzed choroidal areas. This means that the choroidal vascular structure did not differ between eyes with or without cysts. It is known that in CHM patients, CT is normal in early stages of the disease and tends to decrease with age [19]. Nevertheless, despite being a robust tool in clinical research, CT only reflects the total choroidal vasculature with no distinctions between the two stromal and luminal vascular components. Based on this concept, CVI evaluation is more informative compared to CT measurement alone [9].

The CVI, a ratio of LCA over TCA, has been applied to various chorioretinal diseases [10,20,21], including many inherited retinal dystrophies [12,22]. Wei et al. found a decreased CVI in patients with RP, cone-rod dystrophy, Stargardt disease, Bietti crystalline dystrophym, and Best disease [22]. Recently, Iovino et al. investigated the choroidal features associated with the presence of CME in eyes with RP, reporting an increased CT and decreased CVI in eyes with intraretinal fluid [12]. The authors speculated that the thicker choroid in RP patients with intraretinal fluid may result from locally increased blood flow secondary to intraocular inflammation, leading to the development of CME [12]. 
In our study, TCA, LCA, and SCA were all decreased in eyes with CSs at $6 \mathrm{~mm}$ choroidal analysis, and all these findings were also reflected at $1500 \mu \mathrm{m}$ choroidal analysis, although none of these differences were significant. Moreover, as CVI is a ratio of LCA over TCA, it only changes significantly if one of the two choroidal parameters varies more than the other. Murro et al. recently reported no differences in the CVI between young CHM patients and controls, proposing a simultaneous, proportional impairment of both the stromal and luminal components of the choroid in the early stage of the disease [11]. Notwithstanding, they did not make any distinctions between eyes with or without CSs.

Regarding the location of the cysts, our results confirmed the observations of previous authors who described INL as the major cystoid location [5,7]. Additionally, some authors reported the presence of degenerative cysts mainly located in the INL at the transition zone where RPE and outer retinal layers are severely damaged with underlying areas of residual choroidal tissue [8]. Injury of the Muller cells was proposed as the main pathogenetic factor leading to CSs onset in CHM patients [8].

The damage of the outer retinal bands (EZ and ELM) under the cysts in $88.2 \%$ of the eyes found in our cohort seems to further confirm this hypothesis.

Conversely, cystoid changes in RP and X-linked retinoschisis are usually located over preserved outer retina layers [23-25].

ORTs or rosette-like structures have been described in the setting of several chorioretinal disorders [26-28]. Although the pathogenic mechanism leading to the formation of the tubules remains uncertain, onset of ORTs correlates with the damage of photoreceptors and/or RPE, and has been proposed as a prognostic feature of disease severity [26]. The higher incidence of ORTs in the CS group, together with the outer retinal band alterations under the cysts, seems to indicate a degenerative nature of the CSs in patients with CHM.

Macular cysts in retinal dystrophy may develop because of tissue loss secondary to disruption of the retinal architecture, and typically these cystoid changes show minimal or no leakage on fluorescein angiography (FA) [29].

In noninflammatory optic neuropathies including dominant optic atrophy and Leber hereditary optic neuropathy, cysts in the INL are thought to be due to transsynaptic degeneration [30]. Moreover, cysts seem to be more prevalent in younger patients with an intact vitreous base, suggesting that vitreous traction may have a role in CSs development [30].

A discrepancy between the presence of cysts on OCT and visual acuity in some patients with retinal dystrophy has also been reported [31]. In fact, as seen in our study, increased CMT does not always correlate with worse BCVA.

Immunochemical studies showed the presence of carbonic anhydrase enzymes in the $\mathrm{RPE}$, as well as in different cells of the neural retina [32,33].

Carbonic anhydrase inhibitors mediate RPE fluid transfer across the outer bloodretinal barrier, and this may further support the choroid as an important therapeutic target in eyes with CME. Several studies confirmed the efficacy of carbonic anhydrase inhibitors in several retinal dystrophies complicated by CSs $[18,29,34]$, although the evidence of these clinical effects on patients with CHM is very limited [18,35]. Progressive atrophy of the RPE and the choroid may explain the limited action of carbonic anhydrase inhibitors in CHM patients.

The main limitations of the current study included its retrospective nature and the relatively small sample size. Subgroup analyses may not have been powered to identify statistically significant differences. Additionally, we excluded eyes with incomplete visualization of the choroid. Patients with advanced-stage CHM often have optic media opacities, and it is possible that excluding such cases may represent an additional potential confounder. FA was not performed to identify any macular leakage, and the presence of a posterior vitreous detachment was not ascertained with OCT or ocular ultrasound.

In conclusion, our study did not show any significant association of various choroidal parameters with the presence of CSs in CHM patients. Our results suggest that intraretinal cysts overlying damaged outer retinal layers may be the result of degenerative more than exudative processes. Further studies are warranted to provide new insights into 
the intraretinal fluid pathogenesis and to facilitate the development of more efficacious treatment strategies.

Author Contributions: Conceptualization, C.I. and F.S.; data curation, C.I., V.D.I., F.T., V.B., P.M., K.K.V. and J.C.; formal analysis, C.I., V.D.I., V.B., P.M., K.K.V. and J.C.; funding acquisition, F.S.; investigation, C.I., V.D.I., F.T., P.M. and F.S.; methodology, C.I., V.D.I., P.M., K.K.V., J.C. and F.S.; project administration, C.I. and F.S.; resources, F.S.; Software, C.I., K.K.V. and F.S.; supervision, C.I., F.T., J.C. and F.S.; validation, C.I., V.D.I., F.T., P.M. and F.S.; visualization, C.I. and V.D.I.; writingoriginal draft, C.I. and V.D.I.; writing—-review and editing, C.I., V.D.I., F.T., P.M., J.C. and F.S. All authors have read and agreed to the published version of the manuscript.

Funding: This study was supported by the University of Campania "Luigi Vanvitelli" under "VALERE: VanviteLli pEr la RicErca" program (S.B. and F.S.).

Institutional Review Board Statement: This study was conducted according to the guidelines of the Declaration of Helisinki, and approved by the Ethics Committe of the University of Campania "Luigi Vanvitelli" (protocol n. 8189/2015, 09.04.2015).

Informed Consent Statement: Informed consent was obtained from all subjects involved in the study.

Data Availability Statement: Data available from authors.

Acknowledgments: We thank the participating patients and their families. We are grateful to the European Reference Network dedicated to Rare Eye Diseases (ERN-EYE) for useful discussions.

Conflicts of Interest: The authors declare no conflict of interest.

\section{References}

1. Mitsios, A.; Dubis, A.M.; Moosajee, M. Choroideremia: From genetic and clinical phenotyping to gene therapy and future treatments. Ther. Adv. Ophthalmol. 2018, 10, 2515841418817490. [CrossRef]

2. Aleman, T.S.; Han, G.; Serrano, L.W.; Fuerst, N.M.; Charlson, E.S.; Pearson, D.J.; Chung, D.C.; Traband, A.; Pan, W.; Ying, G.S.; et al. Natural History of the Central Structural Abnormalities in Choroideremia: A Prospective Cross-Sectional Study. Ophthalmology 2017, 124, 359-373. [CrossRef] [PubMed]

3. Sorsby, A.; Franceschetti, A.; Joseph, B.R.; Davey, J.B. Choroideremia: Clinical and genetic aspects. Br. J. Ophthalmol. 1952, 36, 547-581. [CrossRef]

4. Xue, K.; Oldani, M.; Jolly, J.K.; Edwards, T.L.; Groppe, M.; Downes, S.M.; Maclaren, R.E. Correlation of optical coherence tomography and autofluorescence in the outer retina and choroid of patients with choroideremia. Investig. Ophthalmol. Vis. Sci. 2016, 57, 3674-3684. [CrossRef] [PubMed]

5. Heon, E.; Alabduljalil, T.; McGuigan, D.B.; Cideciyan, A.V.; Li, S.; Chen, S.; Jacobson, S.G. Visual function and central retinal structure in choroideremia. Investig. Ophthalmol. Vis. Sci. 2016, 57, OCT377-OCT387. [CrossRef] [PubMed]

6. Di Iorio, V.; Esposito, G.; De Falco, F.; Boccia, R.; Fioretti, T.; Colucci, R.; De Rosa, G.; Melillo, P.; Salvatore, F.; Simonelli, F.; et al. $\mathrm{CHM} / \mathrm{REP} 1$ transcript expression and loss of visual function in patients affected by choroideremia. Investig. Ophthalmol. Vis. Sci. 2019, 60, 1547-1555. [CrossRef]

7. Genead, M.A.; Fishman, G.A. Cystic macular oedema on spectral-domain optical coherence tomography in choroideremia patients without cystic changes on fundus examination. Eye 2011, 25, 84-90. [CrossRef]

8. Murro, V.; Mucciolo, D.P.; Giorgio, D.; Sodi, A.; Passerini, I.; Bacci, G.; Bargiacchi, S.; Virgili, G.; Rizzo, S. Optical coherence tomography (OCT) features of cystoid spaces in choroideremia (CHM). Graefe's Arch. Clin. Exp. Ophthalmol. 2019, 257, 2655-2663. [CrossRef]

9. Agrawal, R.; Ding, J.; Sen, P.; Rousselot, A.; Chan, A.; Nivison-Smith, L.; Wei, X.; Mahajan, S.; Kim, R.; Mishra, C.; et al. Exploring choroidal angioarchitecture in health and disease using choroidal vascularity index. Prog. Retin. Eye Res. 2020, 77, 100829. [CrossRef]

10. Iovino, C.; Pellegrini, M.; Bernabei, F.; Borrelli, E.; Sacconi, R.; Govetto, A.; Vagge, A.; Di Zazzo, A.; Forlini, M.; Finocchio, L.; et al. Choroidal Vascularity Index: An In-Depth Analysis of This Novel Optical Coherence Tomography Parameter. J. Clin. Med. 2020, 9, 595. [CrossRef]

11. Murro, V.; Mucciolo, D.P.; Giorgio, D.; Passerini, I.; Cipollini, F.; Virgili, G.; Giansanti, F.; Sodi, A. Choroidal Vascularity Index in young Choroideremia patients. Retina 2020. [CrossRef] [PubMed]

12. Iovino, C.; Au, A.; Hilely, A.; Violanti, S.; Peiretti, E.; Gorin, M.B.; Sarraf, D. Evaluation of the Choroid in Eyes With Retinitis Pigmentosa and Cystoid Macular Edema. Investig. Opthalmol. Vis. Sci. 2019, 60, 5000-5006. [CrossRef] [PubMed]

13. Esposito, G.; De Falco, F.; Tinto, N.; Testa, F.; Vitagliano, L.; Tandurella, I.C.M.; Iannone, L.; Rossi, S.; Rinaldi, E.; Simonelli, F.; et al. Comprehensive mutation analysis (20 families) of the choroideremia gene reveals a missense variant that prevents the binding of REP1 with rab geranylgeranyl transferase. Hum. Mutat. 2011, 32, 1460-1469. [CrossRef] [PubMed] 
14. Agrawal, R.; Wei, X.; Goud, A.; Vupparaboina, K.K.; Jana, S.; Chhablani, J. Influence of scanning area on choroidal vascularity index measurement using optical coherence tomography. Acta Ophthalmol. 2017, 95, e770-e775. [CrossRef]

15. Rasheed, M.A.; Sahoo, N.K.; Goud, A.; Vupparaboina, K.K.; Chhablani, J. Qualitative comparison of choroidal vascularity measurement algorithms. Indian J. Ophthalmol. 2018, 66, 1785-1789.

16. Iovino, C.; Au, A.; Chhablani, J.; Parameswarappa, D.C.; Rasheed, M.A.; Cennamo, G.; Cennamo, G.; Montorio, D.; Ho, A.C.; Xu, D.; et al. Choroidal Anatomic Alterations After Photodynamic Therapy for Chronic Central Serous Chorioretinopathy: A Multicenter Study. Am. J. Ophthalmol. 2020, 217, 104-113. [CrossRef]

17. Iovino, C.; Chhablani, J.; Rasheed, M.A.; Tatti, F.; Bernabei, F.; Pellegrini, M.; Giannaccare, G.; Peiretti, E. Effects of different mydriatics on the choroidal vascularity in healthy subjects. Eye 2020. [CrossRef]

18. Salvatore, S.; Fishman, G.A.; Genead, M.A. Treatment of cystic macular lesions in hereditary retinal dystrophies. Surv. Ophthalmol. 2013, 58, 560-584. [CrossRef]

19. Khan, K.N.; Islam, F.; Moore, A.T.; Michaelides, M. Clinical and Genetic Features of Choroideremia in Childhood. Ophthalmology 2016, 123, 2158-2165. [CrossRef]

20. Pellegrini, M.; Bernabei, F.; Mercanti, A.; Sebastiani, S.; Peiretti, E.; Iovino, C.; Casini, G.; Loiudice, P.; Scorcia, V.; Giannaccare, G. Short-term choroidal vascular changes after aflibercept therapy for neovascular age-related macular degeneration. Graefe's Arch. Clin. Exp. Ophthalmol. 2020. [CrossRef]

21. Giannaccare, G.; Pellegrini, M.; Sebastiani, S.; Bernabei, F.; Moscardelli, F.; Iovino, C.; Napoli, P.E.; Campos, E. Choroidal vascularity index quantification in geographic atrophy using binarization of enhanced-depth imaging optical coherence tomographic scans. Retina 2020, 40, 960-965. [CrossRef]

22. Wei, X.; Mishra, C.; Kannan, N.B.; Holder, G.E.; Khandelwal, N.; Kim, R.; Agrawal, R. Choroidal structural analysis and vascularity index in retinal dystrophies. Acta Ophthalmol. 2019, 97, e116-e121. [CrossRef] [PubMed]

23. Makiyama, Y.; Oishi, A.; Otani, A.; Ogino, K.; Nakagawa, S.; Kurimoto, M.; Yoshimura, N. Prevalence and spatial distribution of cystoid spaces in retinitis pigmentosa: Investigation with spectral domain optical coherence tomography. Retina 2014, 34, 981-988. [CrossRef]

24. Sergouniotis, P.I.; Davidson, A.E.; Lenassi, E.; Devery, S.R.; Moore, A.T.; Webster, A.R. Retinal structure, function, and molecular pathologic features in gyrate atrophy. Ophthalmology 2012, 119, 596-605. [CrossRef]

25. Murro, V.; Mucciolo, D.P.; Sodi, A.; Passerini, I.; Giorgio, D.; Virgili, G.; Rizzo, S. Novel clinical findings in autosomal recessive NR2E3-related retinal dystrophy. Graefe's Arch. Clin. Exp. Ophthalmol. 2019, 257, 9-22. [CrossRef]

26. Goldberg, N.R.; Greenberg, J.P.; Laud, K.; Tsang, S.; Freund, K.B. Outer retinal tubulation in degenerative retinal disorders. Retina 2013, 33, 1871-1876. [CrossRef]

27. Dolz-Marco, R.; Litts, K.M.; Tan, A.C.S.; Freund, K.B.; Curcio, C.A. The Evolution of Outer Retinal Tubulation, a Neurodegeneration and Gliosis Prominent in Macular Diseases. Ophthalmology 2017, 124, 1353-1367. [CrossRef]

28. Mandadi, S.K.R.; Iovino, C.; Sacconi, R.; Querques, G.; Peiretti, E.; Singh, S.R.; Chhablani, J. Outer retinal tubulations in central serous chorioretinopathy associated with choroidal neovascularisation. Eur. J. Ophthalmol. 2020. [CrossRef] [PubMed]

29. Ganesh, A.; Stroh, E.; Manayath, G.J.; Al-Zuhaibi, S.; Levin, A.V. Macular cysts in retinal dystrophy. Curr. Opin. Ophthalmol. 2011, 22, 332-339. [CrossRef]

30. Jiramongkolchai, K.; Bhatti, M.T.; Proia, A.; Freedman, S.F.; El-Dairi, M.A. Formation of macular inner nuclear layer cysts in optic atrophy. Investig. Ophthalmol. Vis. Sci. 2016, 57, 989-991. [CrossRef] [PubMed]

31. Hirakawa, H.; Iijima, H.; Gohdo, T.; Tsukahara, S. Optical coherence tomography of cystoid macular edema associated with retinitis pigmentosa. Am. J. Ophthalmol. 1999, 128, 185-191. [CrossRef]

32. Wolfensberger, T.J.; Mahieu, I.; Jarvis-Evans, J.; Boulton, M.; Carter, N.D.; Nogradi, A.; Hollande, E.; Bird, A.C. Membrane-bound carbonic anhydrase in human retinal pigment epithelium. Investig. Ophthalmol. Vis. Sci. 1994, 35, 3401-3407.

33. Moldow, B.; Sander, B.; Larsen, M.; Lund-Andersen, H. Effects of acetazolamide on passive and active transport of fluorescein across the normal BRB. Investig. Ophthalmol. Vis. Sci. 1999, 40, 1770-1775.

34. Testa, F.; Di Iorio, V.; Gallo, B.; Marchese, M.; Nesti, A.; De Rosa, G.; Melillo, P.; Simonelli, F. Carbonic anhydrase inhibitors in patients with X-linked retinoschisis: Effects on macular morphology and function. Ophthalmic Genet. 2019, 40, 207-212. [CrossRef] [PubMed]

35. Genead, M.A.; McAnany, J.J.; Fishman, G.A. Topical dorzolamide for treatment of cystoid macular edema in patients with choroideremia. Retina 2012, 32, 826-833. [CrossRef] [PubMed] 